\title{
Structural insights into the membrane-extracted dimeric form of the ATPase TraB from the Escherichia coli pKM101 conjugation system
}

\author{
Eric Durand ${ }^{1,3}$, Gabriel Waksman ${ }^{1 *}$, Veronique Receveur-Brechot ${ }^{2 *}$
}

\begin{abstract}
Background: Type IV secretion (T4S) systems are involved in secretion of virulence factors such as toxins or transforming molecules, or bacterial conjugation. T4S systems are composed of 12 proteins named VirB1-B11 and VirD4. Among them, three ATPases are involved in the assembly of the T4S system and/or provide energy for substrate transfer, VirB4, VirB11 and VirD4. The X-ray crystal structures of VirB11 and VirD4 have already been solved but VirB4 has proven to be reluctant to any structural investigation so far.

Results: Here, we have used small-angle X-ray scattering to obtain the first structural models for the membraneextracted, dimeric form of the TraB protein, the VirB4 homolog encoded by the E. coli pKM101 plasmid, and for the monomeric soluble form of the LvhB4 protein, the VirB4 homolog of the T4S system encoded by the Legionella pneumophila I wh operon. We have obtained the low resolution structures of the full-length TraB and of its $\mathrm{N}$ - and C-terminal halves. From these SAXS models, we derive the internal organisation of TraB. We also show that the two TraB N- and C-terminal domains are independently involved in the dimerisation of the full-length protein.
\end{abstract}

Conclusions: These models provide the first structural insights into the architecture of VirB4 proteins. In particular, our results highlight the modular arrangement and functional relevance of the dimeric-membrane-bound form of TraB.

\section{Background}

Type IV secretion (T4S) systems are one of six secretion systems used to transport effector proteins or DNAs through the cell membrane of Gram-negative bacteria. These six secretions systems can be categorised into two classes. The first class of secretion systems mediates substrate transfer from the cytosol to the extracellular milieu in one step: substrates captured from the cytosol are released extracellularly without the need for a periplasmic intermediate [1]. The second class encompasses a range of specialised outer membrane (OM) secretion systems: the substrate is first transported through the inner membrane (IM) to the periplasm via the general SecABYEG secretion machinery and then uses specialised OM

\footnotetext{
* Correspondence: g.waksman@ucl.ac.uk; Veronique.Brechot@ibsm.cnrs-mrs.fr 'Institute of Structural and Molecular Biology, UCL/Birkbeck, Malet Street, London WC1E 7HX, UK

${ }^{2}$ IMR-CNRS - UPR3243, 31 Chemin Joseph Aiguier, 13402 Marseille Cedex 20, France

Full list of author information is available at the end of the article
}

systems for extracellular release [2,3]. T4S systems belong to the first class.

T4S systems export proteins and DNA-protein complexes and fulfil a wide variety of functions, such as i- the conjugative transfer of plasmids and other mobile DNA elements to bacterial recipient cells, ii- the direct uptake of DNA from the extracellular milieu or iii- the delivery of protein or DNA substrates to eukaryotic target cells $[4,5]$. T4S systems are used by several plant and human pathogens for virulence. Such bacterial pathogens include Agrobacterium tumefaciens, the causative agent of crown gall disease in plants, Bordetella pertussis, the agent responsible for whooping cough in children, and Helicobacter pylori, responsible for gastric ulcers and stomach cancer [6-9]. In addition, there are intracellular bacterial pathogens utilising T4S systems for virulence, such as Brucella suis, the causative agent of brucellosis, and Legionella pneumophila, the causative agent of Legionnaires' disease [10,11].

T4S systems are generally composed of 12 protein components forming a macromolecular assembly inserted into
C Biomed Central

() 2011 Durand et al; licensee BioMed Central Ltd. This is an Open Access article distributed under the terms of the Creative Commons Attribution License (http://creativecommons.org/licenses/by/2.0), which permits unrestricted use, distribution, and reproduction in any medium, provided the original work is properly cited. 
the bacterial cell envelope [5]. These proteins are named VirB1-VirB11 and VirD4, based on the widely used nomenclature of the model system, the A.tumefaciens VirB/D4 T4S system. Three ATPases are key components of the T4S system: VirD4, VirB11 and VirB4. VirB4 proteins are the largest and the most evolutionarily conserved proteins in T4S systems [12] but their function remains unclear. Although VirB4 proteins have clearly defined Walker A and Walker B motifs characteristic of ATPases [13], until very recently no ATPase activity had been demonstrated for any VirB4 homologues [13]. However, two recent studies have shown that ATPase activities of VirB4 proteins are crucially dependent on solution conditions and on the oligomerisation state of VirB4 [14,15]. For TrwK, the VirB4 homolog encoded by the R388 conjugative plasmid system, Rabel et al. [13] initially reported that the protein exhibited no ATPase activity and was monomeric. However Arechaga et al. [14], in a subsequent study, reported an ATPase activity of TrwK in the presence of acetate ions, possibly due to a small proportion of an hexameric form of the protein. TraB, the VirB4 homolog encoded by the pKM101 conjugative plasmid system, also exhibits ATPase activity in the presence of acetate ions and is primarily hexameric under these solution conditions [15]. Interestingly, $\mathrm{TraB}$ partitions between the cytosol and the inner membrane, and the membrane-extracted form does not exhibit ATPase activity, even in the presence of acetate ions [15]. This membrane-extracted form of TraB was also shown to be dimeric. It was concluded that cytosolic TraB is in equilibrium between a dimeric form that binds DNA and nucleotides, but is unable to hydrolyze ATP, and an acetate-induced hexameric form able to hydrolyse ATP. TraB purified from the membrane is in the dimeric form, and is unable to transition to the hexameric form even in the presence of acetate ions [15]. Interestingly, A. tumefaciens VirB4 was also shown to form active dimers in vivo [16], strongly supporting a functional role of this dimer, besides the hexameric form.

The structure of VirB4 proteins is still unknown, as they have resisted extensive crystallisation efforts either in the hexameric or the dimeric form. Attempts at visualising acetate-induced hexameric TraB by negative stained electron microscopy or small-angle X-ray scattering have failed [15]. Recently, based on sequence similarities with TrwB (the VirD4 homolog from the plasmid R388 conjugation system), the A. tumefaciens VirB4 C-terminal domain was modelled, as an homo-hexameric ring [17] much like VirB11 and VirD4 [18]. However no structural experimental data has yet backed this model, most probably because it has been impossible so far to stabilise and isolate the hexameric form of VirB4. Here we report the low resolution structure of the membrane-extracted dimeric form of TraB, using small-angle X-ray scattering (SAXS). We also performed a SAXS analysis of the
$\mathrm{N}$-terminal $\left(\mathrm{TraB}_{\mathrm{NT}}\right)$ and $\mathrm{C}$-terminal $\left(\mathrm{TraB}_{\mathrm{CT}}\right)$ domains of TraB, and of the full-length monomeric LvhB4, the VirB4 homolog from the L. pneumophila T4S system, which represents the first in vitro study of a member of the L. pneumophila lvh T4S system. Altogether, our results provide the first insights into the architecture of the highly conserved VirB4 family of proteins.

\section{Results}

\section{Purification of TraB domains and LvhB4}

Based on sequence homology between the C-terminal domain of TraB and the protein TrwB, the E. coli R388encoded VirD4 homolog, we previously established that TraB can be divided into two folded domains (Figure 1A): a C-terminal domain (residues 448 to 848, $\mathrm{TraB}_{\mathrm{CT}}$ ), which is soluble, and an $\mathrm{N}$-terminal domain (residues 1-442, $\mathrm{TraB}_{\mathrm{NT}}$ ), which partitions between a soluble form in the cytosol and a membrane-bound form [15]. These two domains are functional as they are each able to bind DNA and ATP [15]. Full-length TraB $\left(\operatorname{TraB}_{\mathrm{FL}}\right)$ was subsequently found to partition between a soluble and membrane-bound form [15]. Various transmembrane domains predictors were used to screen the sequence of TraB (DAS, http://www.sbc.su.se/ miklos/DAS/; HMMTOP, http://www.enzim.hu/ hmmtop/; TMPred, http://www.ch.embnet.org/software/ TMPRED_form.html; TMHMM, http://www.cbs.dtu.dk/ services/TMHMM-2.0/; and TopPred, http://mobyle.pasteur.fr/cgi-bin/portal.py?form=toppred). The predictions were not fully consistent, except for one stretch that was predicted by two out of the 5 different predictors, between residues 254 and 271 . This suggests the existence of a transmembrane (TM) segment in TraB, or of a hydrophobic patch through which TraB might be associated with the membrane.

For this study, $\operatorname{TraB}_{\mathrm{FL}}$ and $\mathrm{TraB}_{\mathrm{NT}}$ were both purified from the membrane fraction, while $\operatorname{TraB}_{\mathrm{CT}}$, which is soluble and does not partition in the membrane, was purified from the soluble fraction. For comparison, we cloned, expressed and purified the full-length LvhB4, the VirB4 homolog from the L. pneumophila T4S system, for which no predicted TM domain was found. Indeed, LvhB4 purifies from the soluble fraction and not from the membrane fraction, demonstrating that the protein is not located in the membrane. All four proteins were purified to homogeneity using the same two-step purification strategy (Figure 1B and "Materials \& Methods"). In SDSPAGE the proteins migrate at their expected molecular mass: $102 \mathrm{kDa}$ for $\mathrm{TraB}_{\mathrm{FL}}, 55 \mathrm{kDa}$ for $\operatorname{TraB}_{\mathrm{NT}}, 49 \mathrm{kDa}$ for $\mathrm{TraB}_{\mathrm{CT}}$, and $94 \mathrm{kDa}$ for LvhB4 (Figure $1 \mathrm{~B}$ ).

\section{Size Determination of TraB domains and LvhB4}

We investigated the oligomeric state of all four proteins in the $\mathrm{GF}^{\text {sol }}\left(\mathrm{TraB}_{\mathrm{CT}}\right.$ and LvhB4) and $\mathrm{GF}^{\mathrm{mb}}\left(\mathrm{TraB}_{\mathrm{NT}}\right.$ 

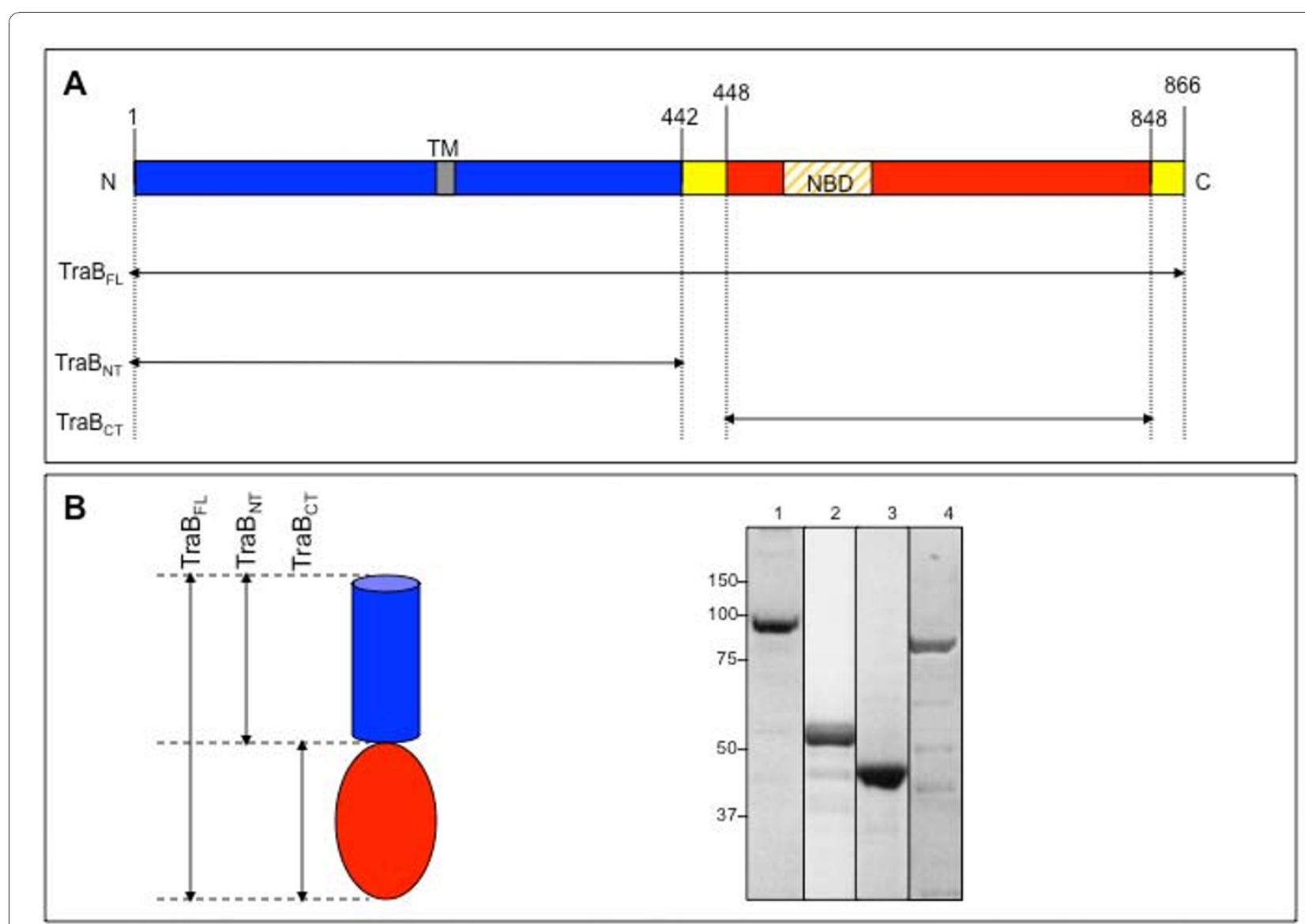

Figure 1 Schematic representation of the domain structures of TraB. (A) N: N-terminus; C: C-terminus; TM: Putative transmembrane domain; NBD: NTP binding domain; FL: TraB full-length (TraB $\mathrm{FL}_{\mathrm{L}}$ : 1-866); NT: TraB N-terminal domain (TraB $\mathrm{NT}_{\mathrm{N}}$ : 1-442); $\mathrm{CT}$ : TraB C-terminal domain (TraB $\mathrm{CT}_{\mathrm{T}}$ : 448-848). (B) NuPAGE 4-12\% showing the purified proteins after gel filtration. (Lane 1) TraB $\mathrm{FL}_{\mathrm{L}}(102 \mathrm{kDa})$; (Lane 2) $\operatorname{TraB}_{\mathrm{NT}}(55 \mathrm{kDa})$; (Lane 3) TraB $\mathrm{CT}$ (48.8 kDa); and (Lane 4) LvhB4 (93.8 kDa). Molecular mass markers are indicated on the left side of the gel $(\mathrm{kDa})$. A transmembrane segment (TM) in $\mathrm{TraB}$ is predicted, between residues 254 and 271.

and $\mathrm{TraB}_{\mathrm{FL}}$ ) buffer conditions (see definition of $\mathrm{GF}^{\text {sol }}$ and $\mathrm{GF}^{\mathrm{mb}}$ in Materials and Methods). Table 1 summarizes the results obtained by Gel Filtration, Dynamic Light Scattering and Native-Gel electrophoresis. The calibration of the gel filtration column (see "Materials \& Methods") allowed us to evaluate the apparent

Table 1 Theoretical and experimental Molecular Mass (MM) determination

\begin{tabular}{llllll}
\hline & MM $^{\text {Calc }}$ & GF calibration & D.L.S & BN-PAGE & Oligomeric state \\
\hline TraB $_{\text {FL }}$ & 103 & 198 & 184 & $146-242$ & Dimer \\
TraB $_{\text {NT }}$ & 55 & 122 & ND & ND & Dimer \\
TraB $_{\text {CT }}$ & 49 & 100 & 100 & $66-146$ & Dimer \\
LvhB4 $^{9}$ & 97 & 93 & 105 & ND & Monomer
\end{tabular}

All MM are given in kDa. "MMCalc" is the MM calculated from the amino-acid sequence, "GF" stands for gel filtration, "DLS" stands for Dynamic Light Scattering, "BN-PAGE" stands for Blue Native-PAGE. The oligomeric state is deduced from the comparison between $M^{\text {Calc }}$ and the experimental MM as determined by the other approaches. "ND" stands for non-determined. molecular mass of the proteins according to their elution volume. $\mathrm{TraB}_{\mathrm{FL}}$ ran as a $198.1 \mathrm{kDa}$ protein, $\mathrm{TraB}_{\mathrm{NT}}$ as a $122.1 \mathrm{kDa}$ protein, $\mathrm{TraB}_{\mathrm{CT}}$ as a $100 \mathrm{kDa}$ protein, and LvhB4 as a $92.7 \mathrm{kDa}$ protein. By comparison with the calculated molecular mass obtained from the amino acid sequence, we concluded that $\mathrm{TraB}_{\mathrm{FL}}$, TraB $\mathrm{N}_{\mathrm{NT}}$ and $\mathrm{TraB}_{\mathrm{CT}}$ were all forming dimers under the examined buffer conditions. In contrast, LvhB4 behaved as a monomer in the same conditions. DLS and blue-native PAGE (BN-PAGE) confirmed these results for TraB $\mathrm{FL}$ and $\operatorname{TraB}_{\mathrm{CT}}$ (Table 1). In conclusion, all TraB-derived constructs form only dimers in solution, whereas LvhB4 forms monomers.

\section{Overall SAXS Parameters}

Small-angle X-ray scattering (SAXS) studies yield information on the size and shape of macromolecules in solution, and also on the oligomerisation state of macromolecules. The overall dimensions of a protein can be evaluated by 
its radius of gyration, $R_{\mathrm{G}}$, while the molecular mass of the scattering particle is inferred from the forward scattering intensity, $I(0)$, both derived from the Guinier law (see Materials and Methods). The scattering curves of all the constructs followed the Guinier law very well (Figure 2) and did not display any sign of aggregation in solution. We determined the molecular mass of each construct of TraB from their experimental $I(0)$ and obtained $219 \mathrm{kDa}$ for $\mathrm{TraB}_{\mathrm{FL}}, 106 \mathrm{kDa}$ for $\mathrm{TraB}_{\mathrm{NT}}$, and $83 \mathrm{kDa}$ for $\mathrm{TraB}_{\mathrm{CT}}$ (Table 2). After comparison with the expected molecular mass of the monomer of each TraB-derived constructs we concluded that all of them were dimers under the examined solution conditions (Table 2). For $\mathrm{TraB}_{\mathrm{FL}}$ and $\mathrm{TraB}_{\mathrm{NT}}$, the molecular masses inferred from the forward scattering intensity are very similar to the theoretical molecular masses calculated from their sequence. This strongly suggests that very few detergent molecules are bound to the proteins, and therefore that the contribution of the detergents to the scattering intensity can be considered as negligible. LvhB4 was confirmed to be a monomer with a molecular mass experimentally calculated to be $116 \mathrm{kDa}$, very close to the expected monomer size of $97 \mathrm{kDa}$. The $I(0)$ determination of the molecular mass of all four proteins were consistent with our biochemical results and confirmed their oligomeric states. These results suggest that both the $\mathrm{N}$ - and $\mathrm{C}$ terminal halves of TraB participate in the dimer interface of the full-length protein.

The radii of gyration measured on the different constructs are summarized in Table 2. Surprisingly, $\operatorname{TraB}_{\mathrm{FL}}$ and $\mathrm{TraB}_{\mathrm{NT}}$ have similar radii of gyration $(58.6 \pm 0.6 \AA$ and $60.3 \pm 0.7 \AA$ respectively), in spite of the molecular mass of $\mathrm{TraB}_{\mathrm{NT}}$ being half of that of $\mathrm{TraB}_{\mathrm{FL}}$. In contrast, the radii of gyration of $\mathrm{TraB}_{\mathrm{CT}}$ and LvhB4 are smaller $(41.5 \pm 0.5 \AA$ and $37.2 \pm 0.6 \AA$ respectively). Proteins of similar radius of gyration may have very different shape and mass depending on their structure. Thus, $\mathrm{TraB}_{\mathrm{FL}}$ and $\operatorname{TraB}_{\mathrm{NT}}$ may have similar $\mathrm{R}_{\mathrm{G}}$ values but different structures. According to the SAXS results, $\operatorname{TraB}_{\mathrm{CT}}$ and consequently $\mathrm{TraB}_{\mathrm{FL}}$ are on average more compact than $\mathrm{TraB}_{\mathrm{NT}}$. The $\mathrm{R}_{\mathrm{G}}$ of $\mathrm{TraB}_{\mathrm{NT}}$ reflects a less compact structure with a lower molecular mass, whereas, the $R_{G}$

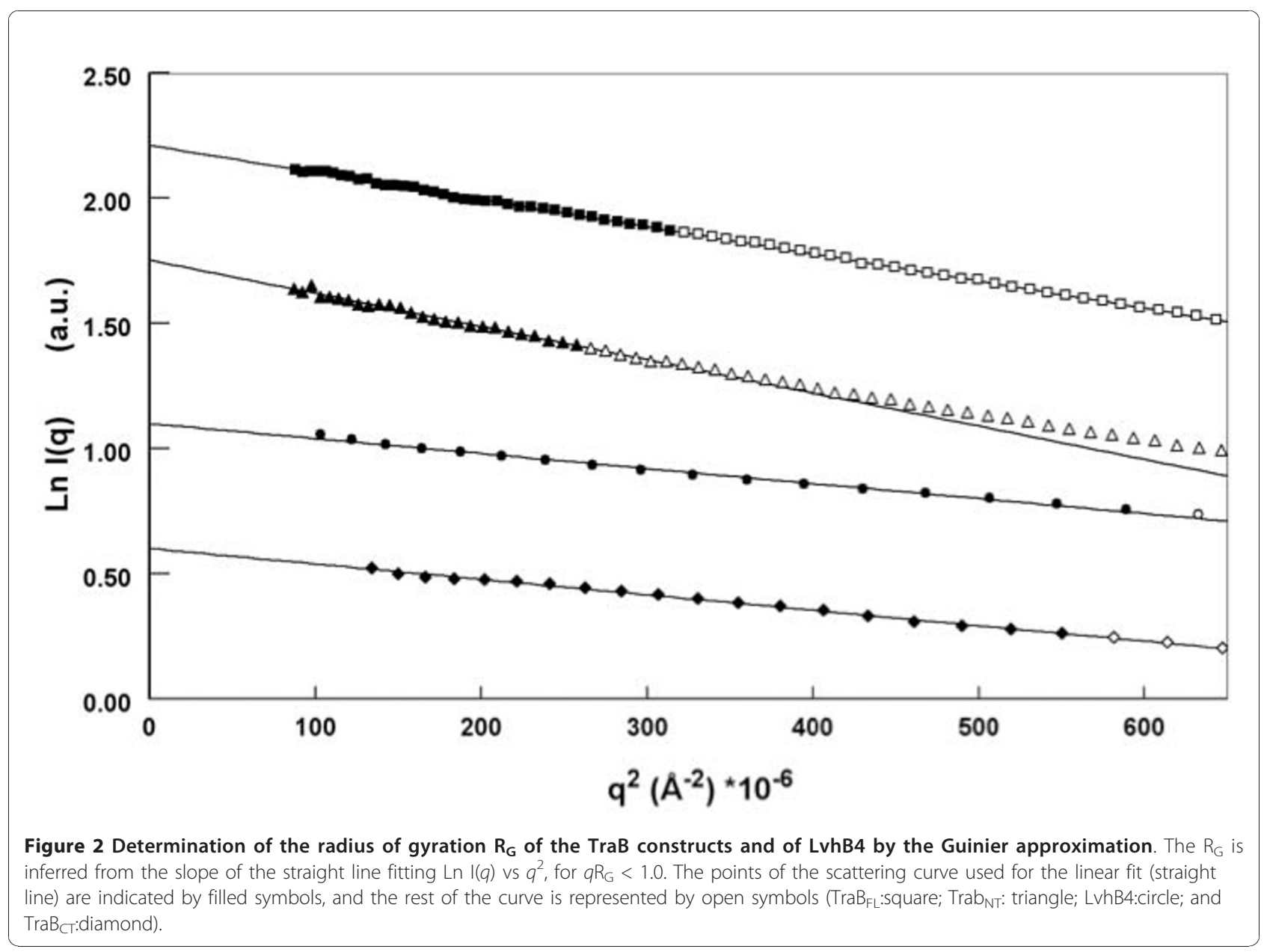


Table 2 Biophysical parameters estimated by SAXS

\begin{tabular}{|c|c|c|c|c|c|c|c|c|c|}
\hline Protein & $\mathrm{MM}_{\text {Calc }}(\mathrm{kDa})$ & $\mathrm{MM}_{\mathrm{Exp}}(\mathrm{kDa})$ & 0.5 & $R_{\mathrm{G}}{ }^{*}(\AA)$ & $R_{\mathrm{G}} *$ (Å) & $D_{\max }(\AA)$ & $R_{\mathrm{G}}^{* * / D_{\max }}$ & $V\left(\AA^{3}\right)$ & GASBOR ChiExp \\
\hline $\operatorname{TraB} \mathrm{FL}_{\mathrm{L}}$ & 103 & 219 & 2 & $58.6 \pm 0.6$ & 58.8 & $198 \pm 2$ & 0.30 & $2.4 \times 10^{5}$ & 1.96 \\
\hline $\operatorname{TraB} B_{N T}$ & 55 & 106 & 2 & $60.3 \pm 0.7$ & 59.2 & $195 \pm 5$ & 0.30 & $1.3 \times 10^{5}$ & 1.56 \\
\hline $\operatorname{TraB} B_{C T}$ & 49 & 83 & 2 & $41.5 \pm 0.5$ & 46.1 & $150 \pm 5$ & 0.31 & $1.1 \times 10^{5}$ & 0.61 \\
\hline LvhB4 & 97 & 116 & 1 & $37.2 \pm 0.6$ & 38.1 & $120 \pm 5$ & 0.32 & $1.1 \times 10^{5}$ & 2.01 \\
\hline$\left(\operatorname{TraB} B_{N T}+\operatorname{TraB} B_{C T}\right) / \operatorname{TraB} B_{F L}$ & 1.01 & 0.86 & & & & & & 1.0 & \\
\hline $2(\mathrm{LvhB} 4) / \operatorname{TraB} \mathrm{F}_{\mathrm{FL}}$ & 0.94 & 1.06 & & & & & & 0.92 & \\
\hline
\end{tabular}

$\mathrm{MM}_{\text {Calc: }}$ Theoretical molecular mass calculated from amino acid sequence. $\mathrm{MM}_{\mathrm{Exp}}$ : Experimentally based molecular mass calculated from the scattering intensity extrapolated at zero angles I(0). O.S: Oligomeric state, as determined by comparison between the $\mathrm{MM}_{\mathrm{Calc}}$ and the $\mathrm{MM}_{\mathrm{Exp}} \cdot R_{\mathrm{G}}{ }^{*}$ : Radius of gyration, estimated from the Guinier plots. $R_{G}{ }^{* *}$ : Radius of gyration, estimated using the program GNOM. $V$ : volume of the envelope calculated by $a b$ initio modelling. ChiExp: discrepancy between the experimental SAXS profile and the fit for each model calculated by the program GASBOR. The ratios of the Molecular Masses and of the volumes between different constructs are given in the last two lines.

of $\mathrm{TraB}_{\mathrm{FL}}$ results from a more compact structure and higher molecular mass, these two parameters counterbalancing each other to yield similar $R_{G}$ values.

We then calculated the pair-distance distribution function, $P(\mathrm{r})$, from the SAXS curves (see "Materials \& Methods"). The $P(\mathrm{r})$ functions for all four constructs exhibited a bell-shaped curve with a slightly extended profile for the higher distances (data not shown), indicating a globular but somewhat elongated conformation. The comparison of the values obtained for the radius of gyration $\left(R_{\mathrm{G}}\right)$ and for the maximum dimension $\left(D_{\max }\right)$ for the four proteins gives an idea of their anisotropy. To obtain an estimation of the anisotropy of the protein, we calculated the ratio between $R_{\mathrm{G}}$ and $D_{\max }$ values for each construct. In the case of a sphere, this ratio is equal to 0.39 , as the radius of a sphere is equal to $(3 / 5)^{1 / 2} R$, where $R$ is the radius of the sphere. Table 2 summarizes the values computed for all the constructs. The ratio $R_{\mathrm{G}} / D_{\max }$ is 0.30 for $\mathrm{TraB}_{\mathrm{FL}}, 0.30$ for $\mathrm{TraB}_{\mathrm{NT}}$, 0.31 for $\operatorname{TraB}_{\mathrm{CT}}$ and 0.32 for LvhB4, significantly different than the value for a sphere, considering the error bars measured on the $\mathrm{R}_{\mathrm{G}}$ and $\mathrm{D}_{\max }$. Interestingly, despite having different sizes, all four constructs exhibit the same anisotropy (ratio $R_{\mathrm{G}} / D_{\max }$ of $\sim 0.3$ ), indicating that the proteins are rather anisotropic, and thus elongated.

\section{Low Resolution Shapes from Ab Initio Modeling}

The overall shapes of the four proteins were computed from the SAXS profiles using the program GASBOR [19]. For all TraB derived constructs $\left(\mathrm{TraB}_{\mathrm{FL}} ; \mathrm{TraB}_{\mathrm{NT}}\right.$ and $\mathrm{TraB}_{\mathrm{CT}}$ ), we used an imposed 2-fold symmetry axis (referred as P2 in GASBOR) for generating the reconstructed models, in agreement with the oligomerisation state inferred from the biochemical data and from the forward scattering intensity $I(0)$. Similar shapes were also obtained without imposing any symmetry (referred as P1 in GASBOR, data not shown). For LvhB4, no symmetry was imposed to reconstruct the 3D-volume. Several independent calculations provided highly reproducible results, with very similar models, and fit to the data of similar quality. The average shapes calculated from repeated, multiple modelling processes (data not shown) give each time a shape similar to the best individual model, defined by the lowest ChiExp value. Figure 3 shows that the fit to the experimental data of these shapes for all four proteins is very good, as confirmed by the value of ChiExp (Table 2). The very reproducible shapes together with the very low ChiExp, obtained when fitting the data (Table 2) give good confidence that the inferred model is not an artifact due to the SAXS intrinsic degeneracy and that these shapes are reliable. We decided to use the best model for each construct as representative of their low resolution structure in solution. Overall, the shapes of the four proteins appear to be globular but rather elongated (Figure 4), as expected from the $R_{\mathrm{G}} / D_{\max }$ ratio. TraB $\mathrm{FL}$ presents two symmetrical lobes with two distinctive protruding ends, with each lobe being potentially attributable to one $\operatorname{TraB}_{\mathrm{FL}}$ monomer in the dimeric assembly (Figure 4A). On the other hand, the shapes of both $\operatorname{TraB}_{\mathrm{NT}}$ (Figure $4 \mathrm{~B}$ ) and $\mathrm{TraB}_{\mathrm{CT}}$ (Figure 4C) appeared to be rather flat and elongated with few protruding extensions. The symmetrical 2 -fold axis separating the two monomers is however clearly visible in the reconstructed volumes, even without imposing any symmetry (data not shown). Interestingly, the low-resolution structure of LvhB4 (Figure 4D) shows an asymmetrical and compact, yet rather extended conformation.

Superposition and comparison of the TraB derived models $\mathrm{TraB}_{\mathrm{NT}}$ and $\mathrm{TraB}_{\mathrm{CT}}$ represent the $\mathrm{N}$ - and $\mathrm{C}$-terminal halves of $\mathrm{TraB}_{\mathrm{FL}}$, respectively (see Figure 1 and "Materials \& Methods"). Thus, given that all the three TraB-derived constructs are dimeric, the sum of the reconstructed volumes of both $\operatorname{TraB}_{\mathrm{NT}}$ and $\operatorname{TraB}_{\mathrm{CT}}$ should give a value similar to the volume of $\mathrm{TraB}_{\mathrm{FL}}$. We used the program CRYSOL [20] to evaluate the volume of the reconstructed models (Table 2). We found that the sum of the volumes of $\operatorname{TraB}_{\mathrm{NT}}$ and $\operatorname{TraB}_{\mathrm{CT}}$ gives a value very close to the volume of $\mathrm{TraB}_{\mathrm{FL}}$ (represented here by the ratio of the volumes being close to 1.0 , see table 2 ). We then manually 


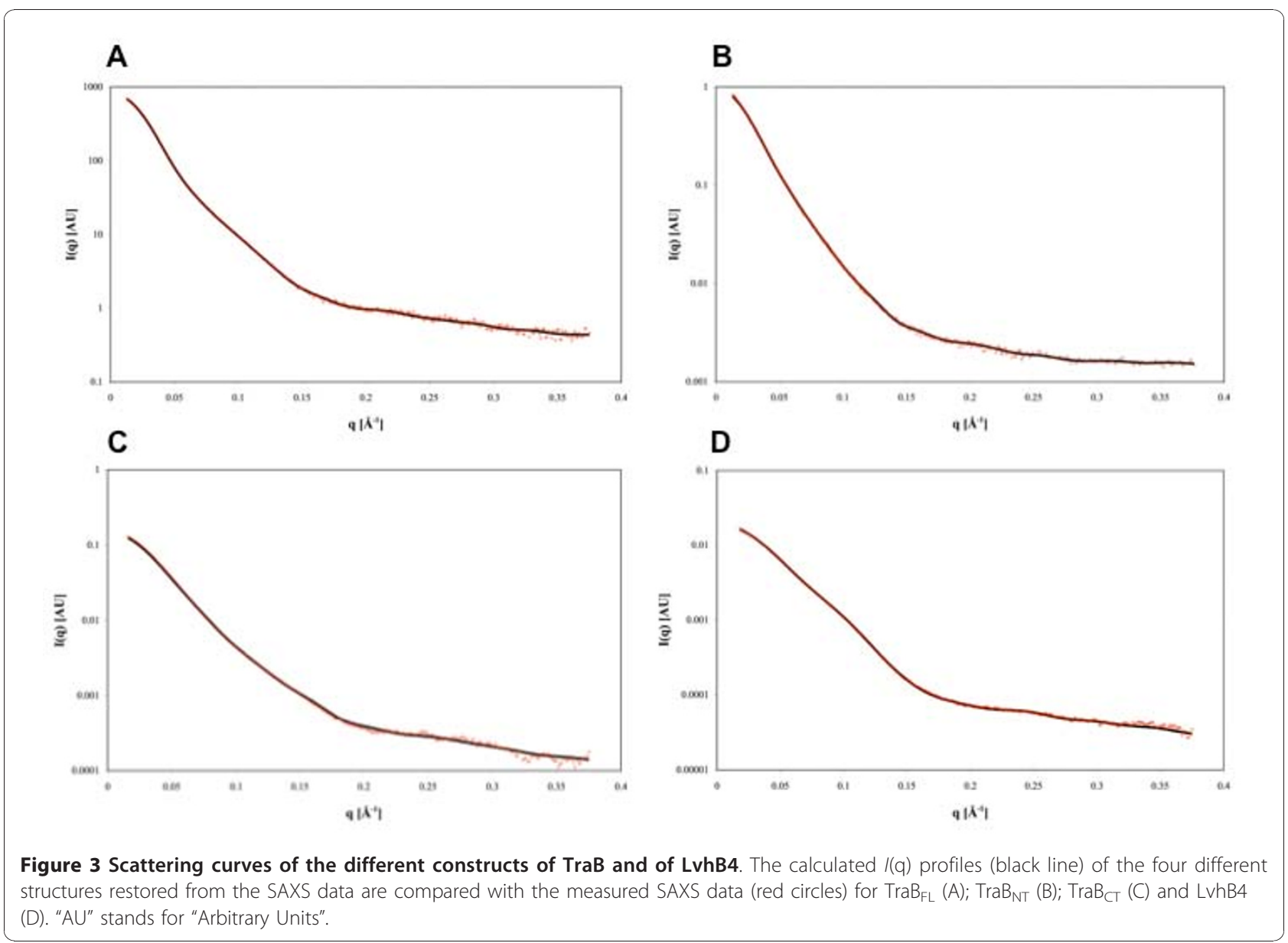

superimposed the shapes of $\mathrm{TraB}_{\mathrm{NT}}$ and $\mathrm{TraB}_{\mathrm{CT}}$ onto the shape of $\mathrm{TraB}_{\mathrm{FL}}$. Several respective orientations of $\mathrm{TraB}_{\mathrm{NT}}$ and $\mathrm{TraB}_{\mathrm{CT}}$ were tested and for only one orientation the $\operatorname{TraB}_{\mathrm{NT}}$ and $\mathrm{TraB}_{\mathrm{CT}}$ models fit well together into the $\mathrm{TraB}_{\mathrm{FL}}$ model without any clash (Figure $5 \mathrm{~A}$ ). In the proposed $\mathrm{TraB}_{\mathrm{FL}}$ model, the longest dimension of $\mathrm{TraB}_{\mathrm{NT}}$ and $\mathrm{TraB}_{\mathrm{CT}}$ are $45^{\circ}$ apart, with the longest dimension of $\mathrm{TraB}_{\mathrm{NT}}$ coinciding with that of the $\mathrm{TraB}_{\mathrm{FL}}$ dimer. In this model, the more compact structure of $\mathrm{TraB}_{\mathrm{CT}}$ lays onto the more elongated structure of $\mathrm{TraB}_{\mathrm{NT}}$ (Figure $5 \mathrm{~B}$ and $5 \mathrm{C})$. Two schemes for the location of the TraB monomer and its two domains can be inferred from these SAXS envelopes of $\mathrm{TraB}_{\mathrm{FL}}$ and $\mathrm{TraB}$ fragments (Figure 5D and $5 \mathrm{E}$ ). In one scheme (dimer 1, Figure 5D), each TraB monomer is positioned on either side of an axis perpendicular to the long axis of the TraB dimer. In the other scheme (dimer 2, Figure $5 \mathrm{E}$ ), each TraB monomer is positioned on each side of the long TraB dimer axis.

\section{Comparison between $\mathrm{TraB}_{\mathrm{FL}}$ and $\mathrm{LvhB} 4$ and orientation of the TraB monomers}

VirB4 proteins are the most conserved components (amino-acid sequence wise) of the T4S systems. It was then logical to think that VirB4 proteins could have a similar shape, albeit with different oligomeric states. We thus hypothesised that if $\mathrm{TraB}_{\mathrm{FL}}$ and LvhB4 monomers (34\% identity) share a similar overall tertiary structure, the latter could help us localise $\mathrm{TraB}_{\mathrm{FL}}$ monomers in the dimeric model. The ratio between the volumes of two LvhB4 monomers and one dimeric $\mathrm{TraB}_{\mathrm{FL}}$ is of the same order as the ratio of their molecular masses, with LvhB4 slightly smaller than $\mathrm{TraB}_{\mathrm{FL}}$ monomers (Table 2 ). Therefore, we tried to manually fit two LvhB4 monomers into the envelope of the $\operatorname{TraB}_{\mathrm{FL}}$ dimer. Figure 6 shows the results obtained with two possible orientations: orientation 1 (Figure 6A and 6B) with each of the LvhB4 monomer being on each side of an axis perpendicular to the $\mathrm{TraB}_{\mathrm{FL}}$ dimer longest axis; and orientation 2 (Figure 6C and 6D) with each LvhB4 monomer being on each side of the longest axis of the $\mathrm{TraB}_{\mathrm{FL}}$ dimer. In Figure 6B and 6D, we have superimposed the schematic diagrams of Figure 5D and $5 \mathrm{E}$, respectively. In both orientations, there remains empty spaces in the $\mathrm{TraB}_{\mathrm{FL}}$ dimer, not filled by two LvhB4 monomers. In the case of orientation 1 , this empty space is localized in between the two monomers. This is not in agreement with the evidence of a stable $\mathrm{TraB}_{\mathrm{FL}}$ dimer and 


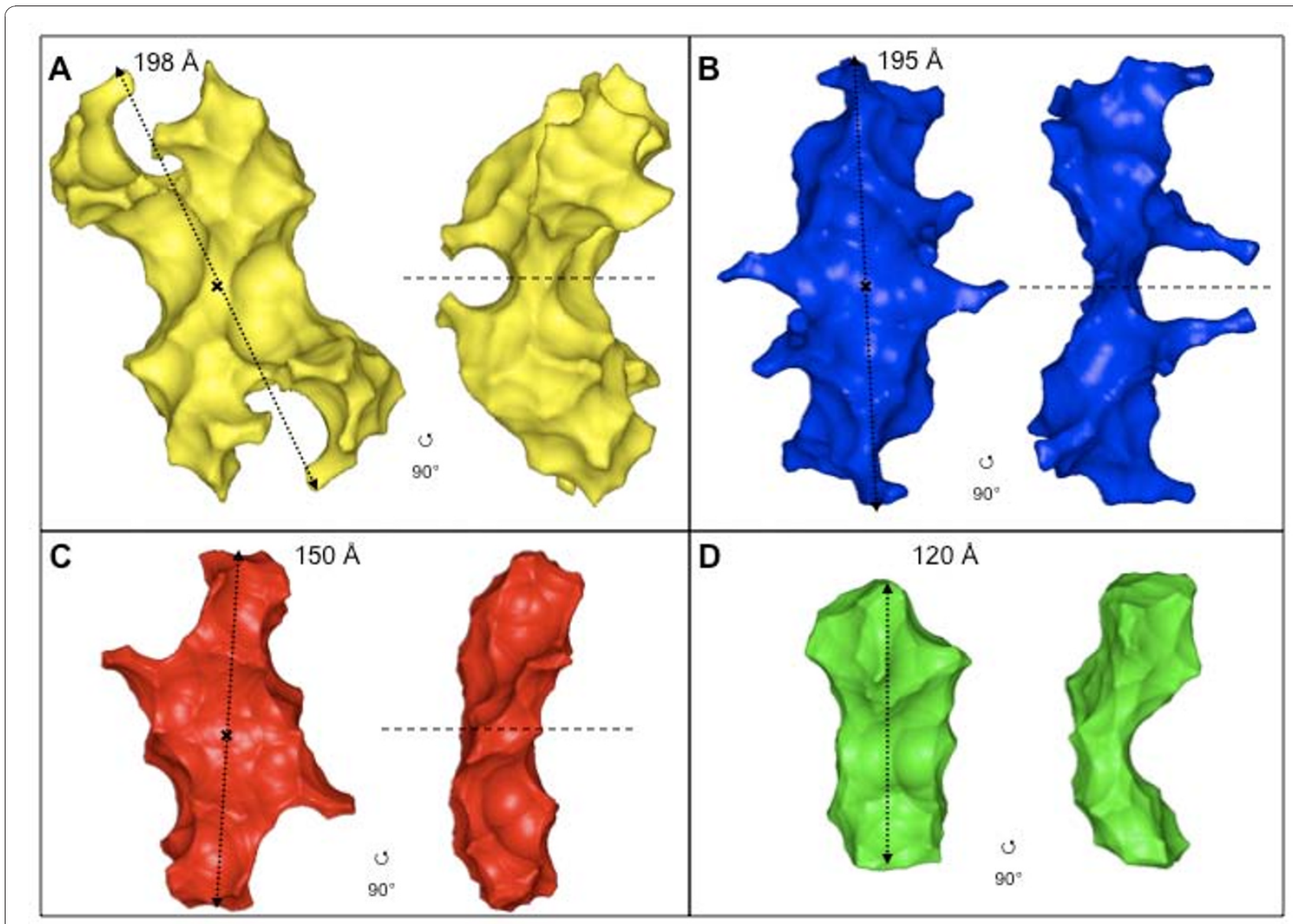

Figure $4 \mathbf{A b}$ initio models of the different constructs of TraB and of LvhB4. Two orientations, rotated along the long axis, of the best models generated by the program GASBOR of $\operatorname{TraB}_{F L}(A) ; \operatorname{TraB}_{N T}(B) ; \operatorname{TraB}_{C T}(C)$ and LvhB4 (D). All TraB models (FL; NT; CT) were generated with an imposed P2 symmetry. The black cross and the dashed-line indicate the P2 symmetry axis between the two monomers in the dimeric model. The double arrow-head dotted-line indicates the maximum dimension $\left(D_{\max }\right)$ of each model.

with the fact that both the $\mathrm{N}$ - and C-terminal domains have been also isolated as dimers. Conversely, in the case of orientation 2, this empty space is localized at the $\mathrm{N}$-terminal ends of LvhB4. This is consistent with the shorter N-terminal domain of LvhB4 compared to TraB and subsequently with the smaller volume of the LvhB4 model compared to the corresponding volume of the $\mathrm{TraB}_{\mathrm{FL}}$ monomer (taken as half of the observed $\mathrm{TraB}_{\mathrm{FL}}$ dimer volume; Table 2). In addition, the contact areas between the two $\mathrm{N}$-terminal domains and the two $\mathrm{C}$-terminal domains are larger, allowing formation of stable $\mathrm{TraB}_{\mathrm{FL}}, \mathrm{TraB}_{\mathrm{NT}}$ and $\mathrm{TraB}_{\mathrm{CT}}$ dimers (see cartoons in Figure $6 \mathrm{D}$ ). In conclusion, we favor orientation 2 as best describing the possible arrangement of the $\mathrm{TraB}_{\mathrm{FL}}$ monomers into the dimeric model.

\section{Comparison between $\mathrm{TraB}_{\mathrm{CT}}$ model and the homology-based structure of At-VirB4}

As mentioned previously, Middleton et al. [17] have modeled the structure of the $\mathrm{C}$-terminal domain of the
A. tumefaciens VirB4 (At-VirB4-Cter) based on the sequence homology with the VirD4 protein TrwB from the R388 conjugation machinery. Since $\mathrm{TraB}$ and $A t$-VirB4 are highly homologous, we used this $A t$-VirB4Cter model and tried to fit two of them into the $\mathrm{TraB}_{\mathrm{CT}}$ dimeric shape. Indeed, as shown in Figure 7 (panel A), we could manually fit the two At-VirB4-Cter models into the $\mathrm{TraB}_{\mathrm{CT}}$ dimer volume. The two $A t$-VirB4-Cter subunits are arranged according to the two-fold symmetry axis of the $\operatorname{TraB}_{\mathrm{CT}}$ dimer. As shown in Figure 7A, this docking identifies the $\mathrm{C}$-terminal end of $\operatorname{TraB}$ as participating in the dimer interface. Similarly, we superimposed the At-VirB4-Cter model with the SAXS envelope of LvhB4 (Figure 7, panel B). From this comparison we propose that the C-terminal domain of LvhB4 is possibly localised at the wider end of the curved shape, opposite to the narrow end. The empty space in the superimposition would consequently be the $\mathrm{N}$-terminal domain of LvhB4. This orientation fits well with the models presented in Figure $6 \mathrm{C}$ and $6 \mathrm{D}$, showing the 


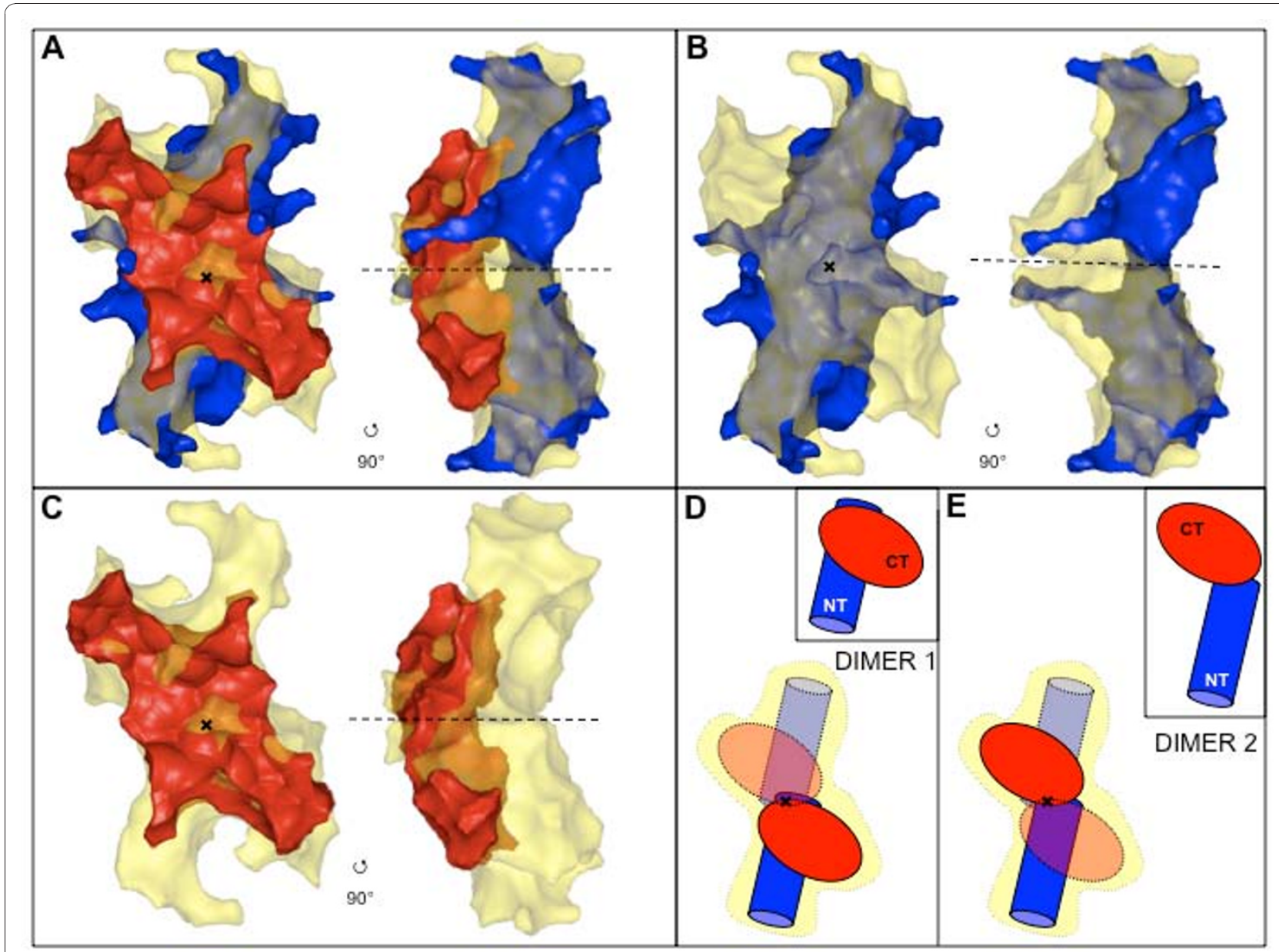

Figure 5 Assembly of TraB-domain SAXS models, reconstituted with the program GASBOR. (A) The TraB $B_{N T}$ (blue) and TraB $B_{C T}$ (red) models are superimposed onto the TraB $B_{L L}$ model (transparent yellow). (B) The TraB $B_{N T}$ model is superimposed onto the TraB $B_{L L}$ model. (C) The TraB $B_{C T}$ model is superimposed onto the TraB $\mathrm{FL}_{\mathrm{L}}$ model. ( $\mathrm{D}$ and $\mathrm{E}$ ) Cartoons representing the domain organisation of TraB deduced from the SAXS models. Two possibilities for the TraB $\mathrm{FL}_{\mathrm{L}}$ monomer are shown, with dimer 1 (D) and dimer 2 (E). The inset shows the TraB $\mathrm{FL}_{\mathrm{L}}$ monomer. In the dimer, one monomer is represented in plain lines without transparency, the other monomer is represented in dotted-lines and transparency. The black cross and the dashed-line both indicate the P2 symmetry axis of the dimeric models. The SAXS models are shown in two orientations, with a $90^{\circ}$ degrees angle rotation along the long axis.

superimposition of two LvhB4 monomers into the $\mathrm{TraB}_{\mathrm{FL}}$ dimeric model.

\section{Discussion}

The SAXS experiments reported here confirm that TraB and its $\mathrm{N}$ - and $\mathrm{C}$-terminal domains are dimeric in the acetate-free solution conditions under which the experiments were conducted, indicating that both domains participate in the dimer interface. The structures of the two domains revealed elongated shapes, which in the full-length protein come together at a $45^{\circ}$ angle. The superposition of the LvhB4 structure could resolve the ambiguity as to where the TraB monomer lies, and favored dimer 2 (Figure 5E), where the monomer would extend along the long axis of the dimer structure. Indeed, in the superimpositions of the two LvhB4 monomers onto the $\mathrm{TraB}_{\mathrm{FL}}$ dimer structure presented in Figure 6B and $6 \mathrm{D}$, only the one aligning the LvhB4 monomers along the long axis of the TraB structure gives rise to an extended dimer interface. The configuration in Figure 5D (Dimer 1) would be expected to yield a less stable dimer than is observed. Also, a more extended conformation of TraB is consistent with our observation that TraB is susceptible to proteolysis and that limited proteolysis of TraB very rapidly yields $\operatorname{TraB}_{\mathrm{CT}}$ (data not shown).

VirB4 is a family of very conserved proteins that are essential components of T4S systems [12] However, recent biochemical studies have revealed that this family of proteins is more diverse than originally expected [13]. For example, their oligomerisation state appears different depending on the system under investigation and the conditions under which they are studied. TraB has 


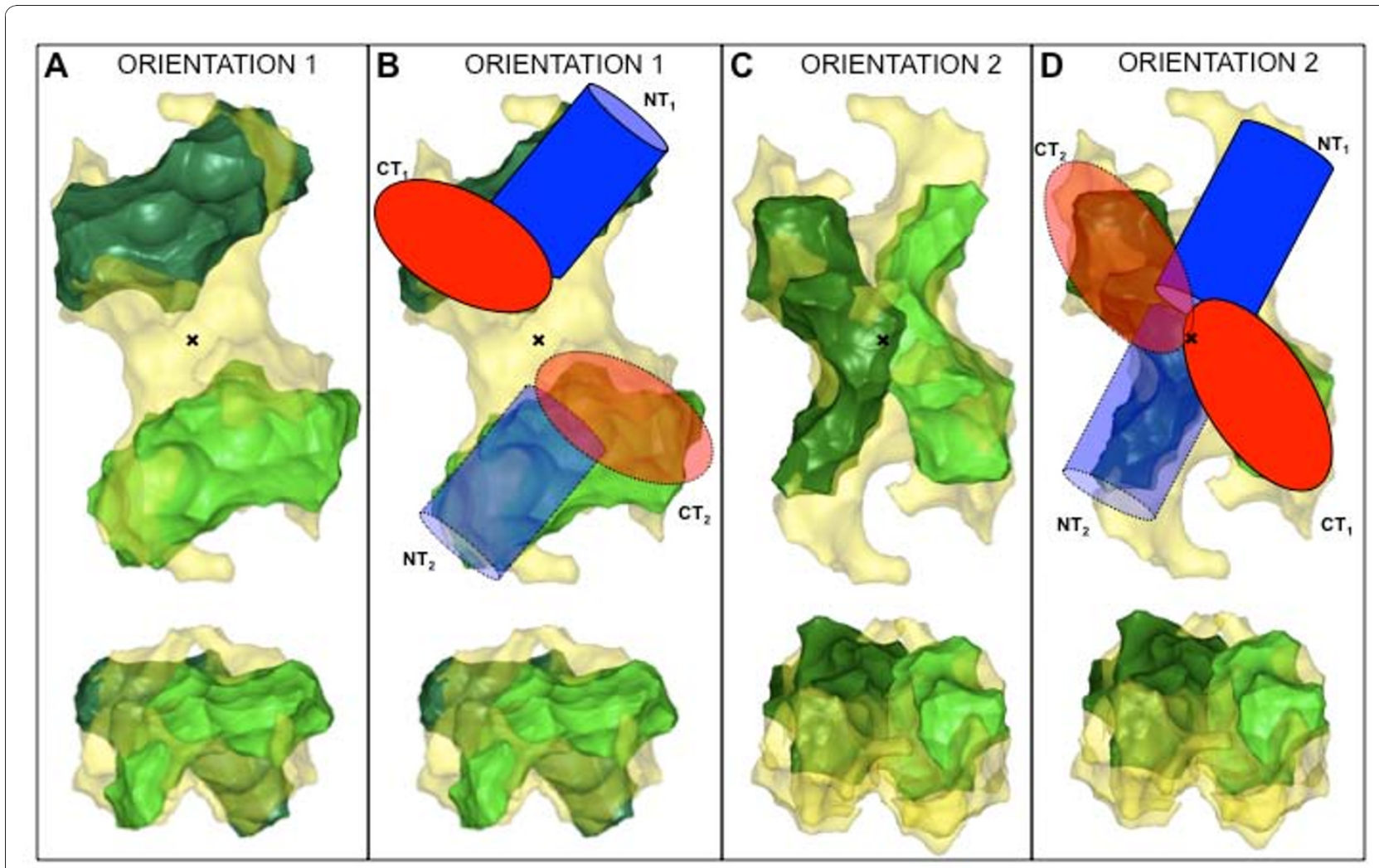

Figure 6 Comparison between $\mathrm{TraB}_{\mathrm{FL}}$ model and LvhB4 model reconstituted from SAXS data. Two possible orientations of two LvhB4 monomers into the TraB $B_{F L}$ model, with (A, ORIENTATION 1)) the two LvhB4 monomers are aligned along the shortest axis of the TraB $\mathrm{FL}_{\mathrm{F}}$ model, or (C, ORIENTATION 2) the two LvhB4 monomers (in light- and dark-green) are aligned along the longest axis of the TraB $\mathrm{FL}_{\mathrm{L}}$ model (in transparent yellow). (B): same as A but for the cartoon representation of TraB in Figure 5D being superimposed. (D): same as C but for the cartoon representation of TraB in Figure 5E being superimposed. Each panel shows two perpendicular views of the model. The two LvhB4 monomers were manually fitted into the TraB $\mathrm{FL}_{\mathrm{L}}$ model. The black cross and the dashed-line both indicate the P2 symmetry axis of the dimeric models.

been shown to be in equilibrium between two oligomeric states, dimer and hexamer, dependent on the solution conditions, namely the presence or absence of acetate ion [15]. TrwK appears to transition between a major monomeric form and minor hexameric form [14]. The VirB4 homolog encoded by the cag pathogenicity island in H. pylori appears to be monomeric [13] and we show here that, under the solution conditions examined, the VirB4 homolog from L. pneumophila LvhB4 is monomeric. Hexamer formation appears to be required for ATP-hydrolyzing activity: indeed only hexameric forms of VirB4 homologs have been shown to exhibit ATPase activity $[14,15]$. So far, only sparse information has been gathered about the function of the dimeric TraB. We recently reported its DNA and nucleotide binding activities [15], while A. tumefaciens VirB4 was shown to direct dimer formation when fused to the $\mathrm{N}$-terminal portion of the cI repressor protein [16]. The different subcellular localisation of TraB together with the recent characterization of a degenerated nucleotide binding site in its $\mathrm{N}$-terminal domain [15] are features also observed in the SecA translocase, perhaps suggesting an evolutionary relationship between the two protein families $[21,22]$. Finally, TraB in the context of the entire T4S machinery might interact with different partners. Indeed, its close association with TraA (the VirB3 homolog encoded by the pKM101 plasmid) or its documented protein-protein interactions with other T4S system components could induce the conformational changes necessary to reshape the active site or radically change its cell environment more specifically, in order to stabilise an active dimeric membrane-bound form.

\section{Conclusions}

The work presented here provides the first structural glimpse of a protein which is crucial to type IV secretion but has until now resisted X-ray crystallography or EM structural characterisation. It uncovers a modular structure that comes together in an extended dimer interface where the domains appear to "hug" each other. The dimers corresponding to each domain could easily be put together in the envelope of the full length protein 


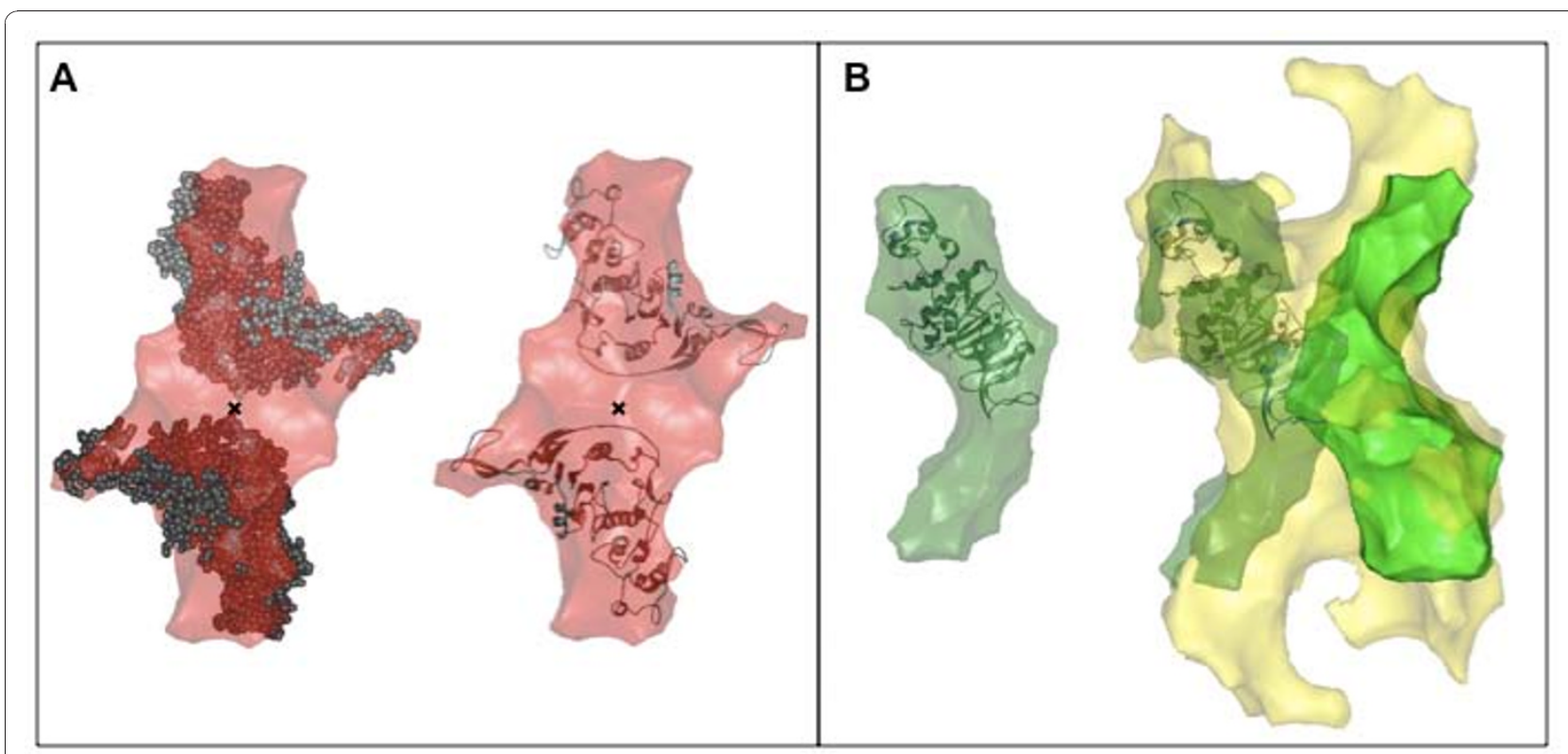

Figure 7 Localisation of the C-terminal domain of At-VirD4, in $\mathrm{TraB}_{\mathrm{CT}}$ and in LvhB4. (A) SAXS model of TraB $\mathrm{B}_{\mathrm{CT}}$ dimer (transparent red surface) superimposed with the At-VirB4-Cter atomic model (in ribbons and CPK representations). The black cross indicates the two-fold symmetry axis of the dimeric TraB $\mathrm{B}_{C T}$ model. (B) SAXS model of LvhB4 monomer (transparent green surface) superimposed with the At-VirB4-Cter atomic model (in ribbons representation); two SAXS models of LvhB4 monomer were fitted into the TraB $\mathrm{FL}_{\mathrm{L}}$ SAXS model (transparent yellow surface). The At-VirB4-Cter monomers were manually fitted into the TraB $B_{C T}$ and LvhB4 models.

and the structural model for LvhB4 helps suggest a potential model for the full-length protein. Intriguingly, the predicted TM segment locates within the N-terminal domain, not at the boundaries of the domain structure. This raises topological issues that can be resolved by a model invoking an orientation of the $\operatorname{TraB}_{\mathrm{NT}}$ domain facing the cytosolic side of the inner membrane, while the $\mathrm{TraB}_{\mathrm{CT}}$ domain would lie in the cytoplasm. This would be consistent with TraB being only superficially associated with the membrane, and therefore being able to partition between the membrane and the cytoplasm. It is also consistent with the dimeric structure proposed here. Docking of the TrwB protein (a potential structural homolog of the C-terminal domain of VirB4 proteins) within the envelope of the $\operatorname{TraB}_{\mathrm{CT}}$ provides further structural details. Finally, the dimeric model of TraB observed here suggests that there might be structural rearrangements required to fit the VirB4 dimeric structure into the 14-fold symmetrical core complex recently unravelled by the high resolution EM structure of the VirB7-VirB9-VirB10 complex [23] and confirmed by the subsequent crystal structure of its outer membrane-inserting part [24]. Further studies will seek to elucidate the crystal structure of a VirB4 protein and also to visualize a complex of VirB4 bound to the core complex.

\section{Methods}

\section{Cloning of TraB domains and LvhB4}

Cloning of the full-length traB gene (tra $\mathrm{B}_{\mathrm{FL}}$, amino acids 1-866; Figure 1), the region encoding the $\mathrm{N}$-terminal domain (tra $\mathrm{B}_{\mathrm{NT}}$, amino acids 1-442; Figure 1$)$ and the C-terminal domain (traB $\mathrm{B}_{\mathrm{CT}}$, amino acids 448-848; Figure 1), together with the full-length $l v h \mathrm{~B} 4$ gene ( $l v h \mathrm{~B} 4$ amino acids 1-826; Legionella pneumophila strain JR32) was as described in Durand et al. [15]. All four constructs allow the expression of $\mathrm{N}$-terminally $\mathrm{His}_{6}$-tagged recombinant proteins, referred to thereafter as $\mathrm{TraB}_{\mathrm{FL}}$, $\mathrm{TraB}_{\mathrm{NT}}$, TraB $\mathrm{C}_{\mathrm{CT}}$, or LvhB4. After DNA sequencing (MWG Biotech) to check that the sequences did not contained any mutation, the four plasmids were transformed by heat-shock in chemically competent BL21 star (DE3) cells (Invitrogen), for large scale production of the recombinant proteins.

\section{Production and Purification of Recombinant Proteins}

E. coli strain BL21 star/DE3 (Invitrogen) containing one of the recombinant plasmids was grown at $37^{\circ} \mathrm{C}$ in Terrific Broth supplemented with $100 \mu \mathrm{g} / \mathrm{ml}$ of Ampicillin

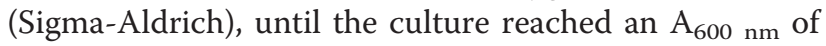
1.2. Cultures were then shifted to $16^{\circ} \mathrm{C}$ for $1 \mathrm{~h}$, before isopropyl- $\beta$-D-thiogalactopyranoside (IPTG) was added to a final concentration of $1 \mathrm{mM}$ and growth continued 
for $15 \mathrm{~h}$ at $16^{\circ} \mathrm{C}$. Cells were harvested by centrifugation, resuspended in $20 \mathrm{mM}$ TrisHCl (pH7.5) and store at $-20^{\circ} \mathrm{C}$.

All subsequent steps were carried out at $4^{\circ} \mathrm{C}$. TraB $\mathrm{TrT}_{\mathrm{CT}}$ and LvhB4 were purified from cytoplasmic extracts as follow. The cells were defrosted and one tablet of Protease inhibitor cocktail EDTA free (Roche) was added, together with $300 \mathrm{mM} \mathrm{NaCl}$ and $1 \mathrm{mM} \beta$-mercaptoethanol ( $\beta M E)$. After cells were broken by two rounds through an EmulsiFlex-C5 homogeniser and DNA fragmentation by sonication, the lysate was clarified by centrifugation at 18,000 r.p.m. for $45 \mathrm{~min}$ in a Sorvall SS-34 rotor. The clarified lysate was loaded onto a HisTrapHP $5 \mathrm{ml}$ column (GE Healthcare) equilibrated in buffer $\mathrm{A}^{\text {sol }}$ (20 mM TrisHCl/pH7.5, $300 \mathrm{mM} \mathrm{NaCl}, 1 \mathrm{mM} \beta \mathrm{ME}$ ) plus $4 \%$ of buffer $\mathrm{B}^{\text {sol }}(20 \mathrm{mM}$ TrisHCl/pH7.5, $300 \mathrm{mM}$ $\mathrm{NaCl}, 1 \mathrm{mM} \beta \mathrm{ME}, 500 \mathrm{mM}$ Imidazole). The column was then washed with $100 \mathrm{ml}$ of buffer $\mathrm{A}^{\text {sol }}$ plus $8 \%$ buffer $\mathrm{B}^{\text {sol }}$. Finally the proteins still bound to the column were eluted in a gradient from $4 \%$ to $100 \%$ of buffer $\mathrm{B}^{\text {sol }}$ in $100 \mathrm{ml}$. Eluted fractions containing either $\operatorname{TraB}_{\mathrm{CT}}$ or LvhB4 were pooled and concentrated in less than $4 \mathrm{ml}$ before being loaded onto a HiPrep 16/60 Sephacryl $\mathrm{S}-300 \mathrm{HR}$ column (Amersham) equilibrated in buffer $\mathrm{GF}^{\text {sol }}$ (20 mM Tris/ $\mathrm{HCl}$ pH 7.5, $50 \mathrm{mM} \mathrm{NaCl}, 1 \mathrm{mM}$ $\beta M E)$. The proteins $\operatorname{TraB}_{\mathrm{CT}}$ and LvhB4 both eluted as a single peak. Fractions under this peak were pooled.

$\mathrm{TraB}_{\mathrm{FL}}$ and $\mathrm{TraB}_{\mathrm{NT}}$ were purified from membrane extracts as followed. The cells were defrosted and one tablet of protease inhibitor cocktail EDTA free (Roche) was added, together with $50 \mathrm{mM} \mathrm{NaCl}$ and $1 \mathrm{mM} \beta \mathrm{ME}$. After cells were broken by two rounds through an EmulsiFlex-C5 homogeniser and DNA fragmentation by sonication, unbroken cells were removed by centrifugation at 14,000 r.p.m. for $10 \mathrm{~min}$ in a Sorvall SS-34 rotor. Total membranes were pelleted by ultracentrifugation (45 min at $100,000 \mathrm{~g}, 4^{\circ} \mathrm{C}$ ) and resuspended in buffer $\mathrm{EB}$ $(20 \mathrm{mM}$ Tris- $\mathrm{HCl} / \mathrm{pH}$ 7.5, $50 \mathrm{mM} \mathrm{NaCl}, 1 \mathrm{mM} \beta \mathrm{ME}$, $1 \%(\mathrm{v} / \mathrm{v})$ Triton $\left.{ }^{\circledR} \mathrm{X}-100\right)$ supplemented with one tablet of protease inhibitor cocktail EDTA free (Roche). Membrane-embedded proteins were extracted during $1 \mathrm{~h}$ at $4^{\circ} \mathrm{C}$. The membrane extract was further clarified by ultracentrifugation $\left(30 \mathrm{~min}\right.$ at $\left.100000 \mathrm{~g}, 4^{\circ} \mathrm{C}\right)$. Triton ${ }^{\mathbb{B}}$ $\mathrm{X}-100$ was only used for extraction, then it was replaced by the hydrogenated Triton ${ }^{\circledR} \mathrm{X}-100^{(\mathrm{H})}$ (Calbiochem) that does not absorb in UV. We further used a concentration of $0.01 \%$ Triton ${ }^{\circledR} \mathrm{X}-100^{(\mathrm{H})}(0.16 \mathrm{mM})$ since it was below the CMC of the detergent $(0.2-0.9 \mathrm{mM})$, thus avoiding the formation of detergent micelles. The cleared extract was loaded onto a HisTrapHP $5 \mathrm{ml}$ column (GE Healthcare) equilibrated in buffer $\mathrm{A}^{\mathrm{mb}}$ $(20 \mathrm{mM}$ TrisHCl/pH7.5, $300 \mathrm{mM} \mathrm{NaCl}, 1 \mathrm{mM} \beta \mathrm{ME}$, $0.01 \%$ Triton $\left.{ }^{\circledR} \mathrm{X}-100^{(\mathrm{H})}\right)$ plus $4 \%$ of buffer $\mathrm{B}^{\mathrm{mb}}(20 \mathrm{mM}$ TrisHCl/pH7.5, $300 \mathrm{mM} \mathrm{NaCl}, 1 \mathrm{mM} \beta \mathrm{ME}, 0.01 \%$
Triton ${ }^{\circledR} \mathrm{X}-100^{(\mathrm{H})}, 500 \mathrm{mM}$ Imidazole). The column was then washed with $100 \mathrm{ml}$ of buffer $\mathrm{A}^{\mathrm{mb}}$ plus $8 \%$ buffer $\mathrm{B}^{\mathrm{mb}}$. Finally the proteins still bound to the column were eluted in a gradient from $4 \%$ to $100 \%$ of buffer $\mathrm{B}^{\mathrm{mb}}$ in $100 \mathrm{ml}$. Eluted fractions containing either ${ }^{\mathrm{His}} \mathrm{TraB}_{\mathrm{FL}}$ or ${ }^{\mathrm{His}} \mathrm{TraB}_{\mathrm{NT}}$ were pooled and concentrated in less than $4 \mathrm{ml}$ before being loaded onto a HiPrep 16/60 Sephacryl S-300 HR column (Amersham) equilibrated in buffer $\mathrm{GF}^{\mathrm{mb}}(20 \mathrm{mM}$ Tris/HCl pH 7.5, $50 \mathrm{mM} \mathrm{NaCl}, 1 \mathrm{mM}$ $\beta M E, 0.01 \%$ Triton $\left.^{\circledR} \mathrm{X}-100^{(\mathrm{H})}\right)$. The proteins $\mathrm{TraB}_{\mathrm{FL}}$ and $\mathrm{TraB}_{\mathrm{NT}}$ both eluted as a single peak. Fractions under this peak were pooled. Apparent molecular mass of proteins eluted from the gel filtration column was deduced from a calibration carried out with low and high molecular mass calibration kits (Amersham Biosciences). Determination of protein concentration was carried out by either using the theoretical absorption coefficients at $280 \mathrm{~nm}$, which were obtained using the program ProtParam on the EXPASY server (available on the World Wide Web at http://www.expasy.ch/tools), or with the Bio-Rad protein assay reagent (Bio-Rad).

\section{Dynamic Light Scattering (DLS)}

Dynamic light scattering experiments were performed with a DynaPro-801 (Protein Solutions) at room temperature. All samples were filtered prior to the measurements (Millex syringe filters, $0.22 \mu \mathrm{m}$; Millipore Corp.). Diffusion coefficients were inferred from the analysis of the decay of the scattered intensity autocorrelation function. The hydrodynamic radius and the molecular mass (MM) of proteins in solution were both deduced from translational diffusion coefficients. All calculations were performed using the software provided by the manufacturer (Dynamics V5.25.44).

\section{SAXS Experiments}

SAXS experiments were performed in two different locations. $\mathrm{TraB}_{\mathrm{FL}}$ and $\mathrm{TraB}_{\mathrm{NT}}$ were analysed on beamline X33 [25] at EMBL-Hamburg on storage ring DORIS III of the Deutsches Elektronen Synchrotron (DESY) using a MAR 345 image plate detector. The scattering patterns from solutions of $\mathrm{TraB}_{\mathrm{FL}}$ at protein concentrations of $3,5,7.5,10$, and $13.5 \mathrm{mg} / \mathrm{ml}$, and for $\mathrm{TraB}_{\mathrm{NT}}$ at protein concentrations of $1.3,2.1,4.9$, and $8.2 \mathrm{mg} / \mathrm{ml}$ were measured in buffer $\mathrm{GF}^{\mathrm{mb}}$. At a sample detector distance of $2.7 \mathrm{~m}$ and wavelength $(\lambda)$ of $1.5 \AA$, the scattering vectors, $q$ ranging from $0.0093 \AA^{-1}$ to 0.50 $\AA^{-1}$ was covered ( $q=4 \pi \sin \theta / \lambda$, where $2 \theta$ is the scattering angle). According to radiation damage tests, one frame of 2 min exposure time was recorded for every sample. The data were normalised to the intensity of the transmitted beam and radially averaged, and the scattering of the buffer was subtracted, as absolutely no trace of the presence of micelles was detected from the buffer 
scattering curve. The difference curves were scaled for protein concentration and extrapolated to yield the final composite scattering curves. Molecular mass calibration was made with BSA.

$\mathrm{TraB}_{\mathrm{CT}}$ and LvhB4 were analysed at the European Synchrotron Radiation Facility (Grenoble, France) on beamline ID02 as described previously [26]. The scattering patterns from solutions of $\mathrm{TraB}_{\mathrm{CT}}$ at protein concentrations of 2.1, 3.7, 4.3, 6.1, and $8.2 \mathrm{mg} / \mathrm{ml}$, and for LvhB4 at protein concentrations of 2, 2.9, 4.6, 6, 7.3, and $8.9 \mathrm{mg} / \mathrm{ml}$ were measured in buffer $\mathrm{GF}^{\text {sol }}$. The wavelength was $1.0 \AA$. The sample-to-detector distances were set at $1.0 \mathrm{~m}\left(\mathrm{TraB}_{\mathrm{CT}}\right)$ and $1.5 \mathrm{~m}(\mathrm{LvhB} 4)$, resulting in scattering vectors, $q$ ranging from $0.011 \AA^{-1}$ to $0.50 \AA^{-1}$ and from $0.010 \AA^{-1}$ to $0.37 \AA^{-1}$ respectively. All experiments were performed at $20^{\circ} \mathrm{C}$. Absolute calibration was made with water.

\section{SAXS Data Evaluation}

All steps for data processing were performed using the program package PRIMUS [27]. The experimental SAXS data for all samples were linear in a Guinier plot of the low $q$ region, indicating that the proteins did not undergo aggregation. The radius of gyration $R_{G}$ was derived by the Guinier approximation $I(q)=I(0) \exp$ $\left(-q^{2} R_{G}^{2} / 3\right)$ for $q R_{G}<1.0$. The radii of gyration $R_{G}$, calculated for different protein concentrations, displayed a slight concentration dependence arising from particle interferences in solution. Interference-free SAXS profiles were estimated by extrapolating the measured scattering curves to infinite dilution. The molecular masses of the solutes were inferred from $I(0)$ values, the forward scattering intensity, which is proportional to the molecular mass of the protein according to relationship $M M \sim I(0) /$ $c$, where $\mathrm{c}$ is the protein concentration. The intensity $I$ (0) was experimentally inferred from the intercept of the linear fit in the Guinier plot $\operatorname{Ln}[I(q)]$ versus $q^{2}$ at low $q$ values $\left(q R_{G}<1.0\right)$. The program GNOM [28] was used to compute the pair-distance distribution functions, $P(r)$. This approach also features the maximum dimension of the macromolecule, Dmax.

\section{Ab Initio Modeling}

The overall shapes of the entire assemblies were restored from the experimental data using the program GASBOR [19]. The scattering profiles were fitted on the spectrum of each protein up to $q=0.37 \AA^{-1}$. GASBOR searches a chain-compatible spatial distribution of an exact number of dummy residues, centred on the $C_{\alpha}$ atoms of the protein amino acid residues. We used both symmetry operations P1 and P2 proposed by the program GASBOR. At least 10 low resolution models obtained from different runs were averaged using the program DAMAVER [29] to construct the average model representing the general structural features of each reconstruction.

\section{Acknowledgements}

This work has been funded by Welcome Trust grant 082227 to GW. We thank Prof. Dr. Hubert Hilbi, ETH Zürich Institute of Microbiology (Switzerland), for providing us with the genomic DNA of Legionella pneumophila. We acknowledge the European Synchrotron Radiation Facility and the Deutsches Elektronen-Synchrotron for provision of synchrotron radiation facilities and we would like to thank, Pierre Panine for assistance in using beamline ID02, and Manfred Roessle for assistance in using beamline X33.

\section{Author details}

${ }^{1}$ Institute of Structural and Molecular Biology, UCL/Birkbeck, Malet Street, London WC1E 7HX, UK. ${ }^{2}$ IMR-CNRS - UPR3243, 31 Chemin Joseph Aiguier, 13402 Marseille Cedex 20, France. ${ }^{3}$ LISM-CNRS - UPR9027, 31 Chemin Joseph Aiguier, 13402 Marseille Cedex 20, France.

\section{Authors' contributions}

VRB and GW designed the study and finalised the manuscript, and ED realised the experiments, analysed the SAXS data with VRB, and drafted the manuscript. All authors read and approved the final manuscript.

Received: 10 September 2010 Accepted: 25 January 2011

Published: 25 January 2011

\section{References}

1. Rego AT, Fronzes R, Waksman G: SnapShot: Bacterial Appendages I. Cell 2010, 140(1):162-162, e161.

2. Fronzes R, Remaut $H$, Waksman G: Architectures and biogenesis of nonflagellar protein appendages in Gram-negative bacteria. EMBO J 2008, 27(17):2271-2280.

3. Rego AT, Chandran V, Waksman G: Two-step and one-step secretion mechanisms in Gram-negative bacteria: contrasting the type IV secretion system and the chaperone-usher pathway of pilus biogenesis. Biochem J 2010, 425(3):475-488.

4. Cascales E, Christie PJ: The versatile bacterial type IV secretion systems. Nat Rev Microbiol 2003, 1(2):137-149.

5. Fronzes R, Christie PJ, Waksman G: The structural biology of type IV secretion systems. Nat Rev Microbiol 2009, 7(10):703-714.

6. Baron $C, O C D$, Lanka E: Bacterial secrets of secretion: EuroConference on the biology of type IV secretion processes. Mol Microbiol 2002, 43(5):1359-1365.

7. Burns DL: Type IV transporters of pathogenic bacteria. Curr Opin Microbiol 2003, 6(1):29-34.

8. Covacci A, Telford JL, Del Giudice G, Parsonnet J, Rappuoli R: Helicobacter pylori virulence and genetic geography. Science 1999, 284(5418):1328-1333.

9. Zupan J, Muth TR, Draper O, Zambryski P: The transfer of DNA from agrobacterium tumefaciens into plants: a feast of fundamental insights. Plant J 2000, 23(1):11-28.

10. Boschiroli ML, Ouahrani-Bettache S, Foulongne V, Michaux-Charachon S, Bourg G, Allardet-Servent A, Cazevieille C, Lavigne JP, Liautard JP, Ramuz M, et al: Type IV secretion and Brucella virulence. Vet Microbiol 2002, 90(14):341-348.

11. Roy $C R$, Tilney $L G$ : The road less traveled: transport of Legionella to the endoplasmic reticulum. J Cell Biol 2002, 158(3):415-419.

12. Fernandez-Lopez R, Garcillan-Barcia MP, Revilla C, Lazaro M, Vielva L, de la Cruz F: Dynamics of the IncW genetic backbone imply general trends in conjugative plasmid evolution. FEMS Microbiol Rev 2006, 30(6):942-966.

13. Rabel C, Grahn AM, Lurz R, Lanka E: The VirB4 family of proposed traffic nucleoside triphosphatases: common motifs in plasmid RP4 TrbE are essential for conjugation and phage adsorption. J Bacteriol 2003, 185(3):1045-1058.

14. Arechaga I, Pena A, Zunzunegui S, Del Carmen Fernandez-Alonso M, Rivas G, de la Cruz F: ATPase activity and oligomeric state of TrwK, the VirB4 homologue of plasmid R388 Type IV secretion system. J Bacteriol 2008. 
15. Durand E, Oomen C, Waksman G: Biochemical dissection of the ATPase TraB, the VirB4 homologue of the Escherichia coli pKM101 conjugation machinery. J Bacteriol 2010, 192(9):2315-2323.

16. Dang TA, Zhou XR, Graf B, Christie PJ: Dimerization of the Agrobacterium tumefaciens VirB4 ATPase and the effect of ATP-binding cassette mutations on the assembly and function of the T-DNA transporter. Mol Microbiol 1999, 32(6):1239-1253.

17. Middleton R, Sjolander K, Krishnamurthy N, Foley J, Zambryski P: Predicted hexameric structure of the Agrobacterium VirB4 $\mathrm{C}$ terminus suggests VirB4 acts as a docking site during type IV secretion. Proc Natl Acad Sci USA 2005, 102(5):1685-1690.

18. Yeo HJ, Savvides SN, Herr AB, Lanka E, Waksman G: Crystal structure of the hexameric traffic ATPase of the Helicobacter pylori type IV secretion system. Mol Cell 2000, 6(6):1461-1472.

19. Svergun DI, Petoukhov MV, Koch MH: Determination of domain structure of proteins from X-ray solution scattering. Biophys J 2001, 80(6):2946-2953.

20. Svergun DI, Barberato C, Koch MHJ: CRYSOL - a Program to Evaluate X-ray Solution Scattering of Biological Macromolecules from Atomic Coordinates. J App/ Cryst 1995, 28:768-773.

21. Cabelli RJ, Dolan KM, Qian LP, Oliver DB: Characterization of membraneassociated and soluble states of SecA protein from wild-type and SecA51(TS) mutant strains of Escherichia coli. J Biol Chem 1991, 266(36):24420-24427.

22. Papanikou E, Karamanou S, Economou A: Bacterial protein secretion through the translocase nanomachine. Nat Rev Microbiol 2007, 5(11):839-851.

23. Fronzes R, Schafer E, Wang L, Saibil HR, Orlova EV, Waksman G: Structure of a type IV secretion system core complex. Science 2009, 323(5911):266-268.

24. Chandran V, Fronzes R, Duquerroy S, Cronin N, Navaza J, Waksman G: Structure of the outer membrane complex of a type IV secretion system. Nature 2009, 462(7276):1011-1015.

25. Maeda Y, Boulin C, Gabriel A, Sumner I, Koch MH: Intensity increases of actin layer-lines on activation of the Limulus muscle. Biophys J 1986, 50(6):1035-1042.

26. Hammel M, Fierobe HP, Czjzek M, Finet S, Receveur-Brechot V: Structural insights into the mechanism of formation of cellulosomes probed by small angle X-ray scattering. J Biol Chem 2004, 279(53):55985-55994.

27. Konarev PV, Volkov W, Sokolova AV, Koch MHJ, Svergun DI: PRIMUS: a Windows PC-based system for small-angle scattering data analysis. J Appl Cryst 2003, 36:1277-1282.

28. Svergun DI: Determination of the Regularization Parameter in IndirectTransform Methods Using Perceptual Criteria. J Appl Cryst 1992, 25:495-503.

29. Volkov W, Svergun DI: Uniqueness of ab inito shape determination in small-angle scattering. J Appl Cryst 2003, 36:860-864.

doi:10.1186/1472-6807-11-4

Cite this article as: Durand et al: Structural insights into the membraneextracted dimeric form of the ATPase TraB from the Escherichia coli pKM101 conjugation system. BMC Structural Biology 2011 11:4.

\section{Submit your next manuscript to BioMed Central and take full advantage of:}

- Convenient online submission

- Thorough peer review

- No space constraints or color figure charges

- Immediate publication on acceptance

- Inclusion in PubMed, CAS, Scopus and Google Scholar

- Research which is freely available for redistribution

Submit your manuscript at www.biomedcentral.com/submit
Biomed Central 